\title{
An inclusive, interdisciplinary forum for worldwide efforts to solve the plastics pollution challenge
}

\author{
Albert A. Koelmans
}

Microplastics and Nanoplastics. What is it that this jour-
nal seeks to achieve? It is often said that there is no silver bullet to the
problem of pollution with plastic debris. Diverse solutions need to be informed by diverse science. They have to come from a diverse suite of measures, such as changing consumer behaviour, addressing the economics of waste, and prioritising material and product design. These are all determined by human decisions and behaviours, implying an urgent need for behavioural science research. Solving the problem through behavioural change and management is a process that can take years, perhaps even decades. Consequently, it is plausible that plastic debris will continue to leach into our environment for many years. This implies that it is essential to understand why and how our economy leads to emissions of plastic debris, how plastic and associated chemicals behave in the environment, and what the risks are to people and the environment on short and long time scales. Data on risks and impacts in the biosphere are also essential for prioritizing solution methods, while such data on actual risks in turn influences the human perception of the problem. Understanding how plastic moves and the plastic problem exists in our socioecological system is key to finding solutions efficiently.

Given the previous it is clear that we need planned multi- and interdisciplinary research as much as we need disciplinary research. Microplastics and Nanoplastics aims to be an inclusive, interdisciplinary forum for worldwide efforts to solve the plastics pollution challenge. That the journal is fully dedicated to all aspects of the plastic challenge is what makes it unique. More specifically, the journal aims to publish innovative high

Correspondence: bart.koelmans@wur.nl

Aquatic Ecology and Water Quality Group, Wageningen University, Wageningen, The Netherlands quality science providing a quantitative and mechanistic understanding of the factors that drive the emissions, fate, effects, risks and societal responses to the presence of plastic debris in nature and society, as well as novel remediation and risk mitigation options and technologies. The journal provides a unified platform for the international reporting of ground-breaking research results and reviews covering the fast-growing area of plastics research. Work across all length scales (macro, micro and nano) and heterogeneous pollutants will be considered. Topics covered include characterization and quantification of plastics; ecotoxicological evaluation; new biodegradable and sustainable materials; waste management methods; the impact of plastics on biodiversity, pollution and human health; social and behavioural science perspectives and policy; transport and accumulation of plastics in the geosphere. This cannot be achieved without a diverse authorship, not only with respect to expertise, but also with respect to gender and geography in hopes of spurring new connections and collaborations between researchers with wide-ranging perspectives across the plastic pollution community.

A final word on the type of papers that we hope to see more. Over the past years the nature of plastics research has evolved. This includes an increase in the quality of the science and an increased awareness of the fact that if we are to solve the 'plastic problem' high quality science is a prerequisite. Accordingly, the Editors of Microplastics and Nanoplastic aim to publish high quality research and will provide publication guidelines to support this aim. The past years several reports and articles have been published that provide guidance for macro- and microplastic research, whereas for nanoplastic similar guidance can be adopted from the research field of engineered nanoparticles. For instance, manuscripts describing the detection, fate, and effects of micro- or

(c) The Author(s). 2021 Open Access This article is licensed under a Creative Commons Attribution 4.0 International License, which permits use, sharing, adaptation, distribution and reproduction in any medium or format, as long as you give appropriate credit to the original author(s) and the source, provide a link to the Creative Commons licence, and indicate if changes were made. The images or other third party material in this article are included in the article's Creative Commons licence, unless indicated otherwise in a credit line to the material. If material is not included in the article's Creative Commons licence and your intended use is not permitted by statutory regulation or exceeds the permitted use, you will need to obtain permission directly from the copyright holder. To view a copy of this licence, visit http://creativecommons.org/licenses/by/4.0/. 
nanoplastic particles ideally adhere to quality assurance / quality control (QA/QC) criteria and report such information explicitly. Use of only visual inspection to identify microplastic particles should be avoided. Natural science studies should explicitly reflect on environmental relevance of the data and take care to not overstate perceived effects. This includes the environmental relevance of the particles and exposure conditions used in effect tests. In all cases particles or items used in tests should be sufficiently characterized given the research aim. At the same time, we strive to always provide balanced assessments leaving room for innovative and pioneering reports, including where the highest standards cannot be met for legitimate reasons. With this, we hope to build a trustworthy source of information for scientists and policymakers, as well as to provide an attractive home for your best research.

Author's contributions

The author(s) read and approve the final manuscript.

\section{Competing interests}

The author declares he has no competing interest.

Published online: 13 January 2021

\section{Publisher's Note}

Springer Nature remains neutral with regard to jurisdictional claims in published maps and institutional affiliations.

\section{Submit your manuscript to a SpringerOpen ${ }^{\circ}$ journal and benefit from:}

- Convenient online submission

- Rigorous peer review

- Open access: articles freely available online

- High visibility within the field

- Retaining the copyright to your article 